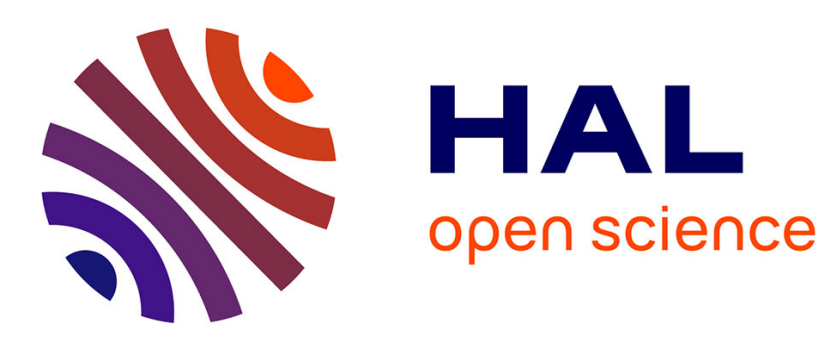

\title{
S1MAWind Tunnel New Aeroacoustic Capability: a Traversing Microphone Array
}

François Nicolas

\section{To cite this version:}

François Nicolas. S1MAWind Tunnel New Aeroacoustic Capability: a Traversing Microphone Array. IAA/CEAS Aeroacoustics Conference, 2018, Jun 2018, ATLANTA, United States. 10.2514/6.20183137. hal-02476244

\author{
HAL Id: hal-02476244 \\ https://hal.science/hal-02476244
}

Submitted on 12 Feb 2020

HAL is a multi-disciplinary open access archive for the deposit and dissemination of scientific research documents, whether they are published or not. The documents may come from teaching and research institutions in France or abroad, or from public or private research centers.
L'archive ouverte pluridisciplinaire HAL, est destinée au dépôt et à la diffusion de documents scientifiques de niveau recherche, publiés ou non, émanant des établissements d'enseignement et de recherche français ou étrangers, des laboratoires publics ou privés. 


\title{
S1MA Wind Tunnel New Aeroacoustic Capability: a Traversing Microphone Array
}

\author{
F. Nicolas* \\ ONERA, Modane, 73500, FRANCE
}

\begin{abstract}
This paper aims at describing the new measurement device installed in S1MA wind tunnel for aeroacoustics tests. We present here the in-situ qualification of a traversing microphone array which equipped the acoustic closed test section of the wind tunnel. First, we show that it allows us to capture very complex directivity patterns thanks to a very good spatial resolution. Secondly, we demonstrate the ability of continuous scans measurements to perform as well as stabilized acquisitions, leading to a major improvement in wind tunnel productivity. Finally, we also take advantage of the microphone array to denoise acquisition data using beamforming processing.
\end{abstract}

\section{Nomenclature}

$\begin{array}{ll}f_{S} & =\text { sampling frequency } \\ \Delta f & =\text { FFT frequency resolution } \\ P S D & =\text { Power Spectrum Density } \\ S P L_{1 / 3} & =\text { Third octave band sound pressure level } \\ \theta & =\text { longitudinal directivity angle } \\ \Delta_{\theta} & =\text { polar directivity sampling } \\ \phi & =\text { azimuthal directivity angle } \\ \phi_{0} & =\text { source azimuthal emission direction } \\ F P & =\text { Fixed Point acquisition } \\ C S & =\text { Continuous Scan acquisition }\end{array}$

\section{Introduction}

Performing acoustic measurement in closed test section wind tunnel remains very challenging. The main causes are the strong background noise, the high reverberant environment and aerodynamic noise on microphones installed into the flow. However, it is of great interest to perform such acquisition simultaneously with good aerodynamic conditions. In addition to flow quality, this goal is also pursued due to time and cost motivations. To make progress towards this objective, some effort has been made those last years in order to improve S1MA acoustic capabilities [1-3].

S1MA is one of the largest atmospheric and sonic wind tunnel in the world. Its aerodynamic circuit represented in Fig. 1 is $390 \mathrm{~m}$ long and the maximum reachable speed in the $8 \mathrm{~m}$ diameter test section is Mach 1 . The wind tunnel have 3 movable carts which allow the preparation of the next test while operating the facility. One of the cart can be equipped with an dedicated acoustic liner up to Mach 0.3 tests. This work, part of the way forward to improve S1MA acoustic capabilities, investigates the use of a traversing acoustic array. The use of such device is of great interest to investigate complex noise sources.

The use of acoustic phased array is now quite common in open-test section wind tunnel for noise source localization. However, only few facilities make use of traversing array for characterizing complex noise source directivity. The Large Low speed Facility (LLF) of DNW use an in-flow wing to probe the noise field around a model (see [4] for example). At NASA Langley, an important work $([5,6])$ has be achieved to update the 14- by 22-foot wind tunnel with a traversing array and two movable microphone towers. This instrumentation allows the exhaustive analysis of the sound field directivity ([7]). In particular, a study of jet engines noise shielding by an hybrid wing body aircraft has been conducted by [8, 9]. Traversing array acquisitions are also used in closed test section facilities such in the Arnold Engineering Development Complex (AEDC) at NASA Ames. Its very large dimensions offer a good opportunity to test different

\footnotetext{
*Research Scientist, PhD, Wind Tunnel Division, francois.nicolas@onera.fr, AIAA Member.
} 


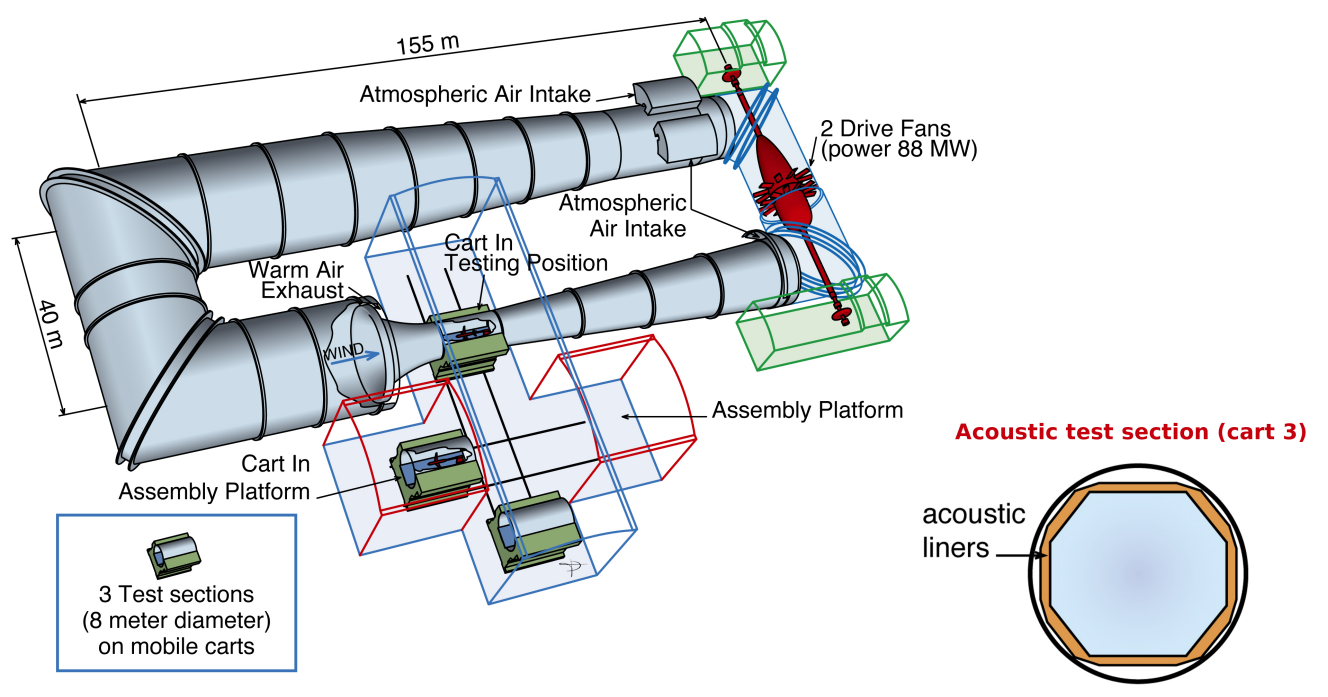

Fig. 1 S1MA wind tunnel facility and its acoustic test section.

traversing arrays $([10,[1])$.In most of the previous studies acoustic arrays are employed at discrete specific positions. On the contrary, [12] suggests to performs continuous acquisitions while moving the acoustic array. By the use of a particular processing techniques, he is able to achieve a high angular directivity resolution for jet engine simulator in the NASA Glenn Research Center's 9- by 15-foot wind tunnel(LSWT).

This work is a preliminary test on the use of a traversing acoustic array in S1MA wind tunnel. We start by describing our experimental setup and also by recalling the instrumentation of S1MA acoustic test section in Section III] Then, in Section IV] we presents far field directivity obtained by the traversing array and our wall-mounted microphones. Section $\mathrm{V}$ focuses on the continuous acquisitions processing and results. Finally, in Section VI] we take benefits of the array to dereverberate acoustic data using conventional beamforming.

\section{Experimental setup}

\section{A. S1MA acoustic test section}

We first describe the classical instrumentation of S1MA acoustic test section and then, the new traversing array device. A whole view of the setup is presented in Fig. 2 .

S1MA acoustic test section is made of $75 \mathrm{~mm}$ thick acoustic foam panels which can be used up to a wind tunnel speed of Mach 0.3. Those panels can be removed for the use of the test section in classical aerodynamic conditions. The test section is equipped with two lines of 18 Bruel and Kjaer $(B \& K)$ Model 4944 1/4 inch far fields microphones: a side line on the starboard side and a flyover line at the ceiling of the test section. Those microphones, flush mounted behind a wiremesh cloth with a recess distance $h=6 \mathrm{~mm}$ are inserted into a block of foam (Fig. (4). This specific mount is based on the recommendations of [13] and has been qualified in an anechoic chamber and also in the wind tunnel in [1]. The left side of the test section is also equipped with two nose cone microphones.

\section{B. Traversing acoustic array}

For the traversing array implementation, a rail has been installed on the wind tunnel wall behind the acoustic panels. It covers almost the entire test section length over a distance of $10 \mathrm{~m}$. The array is moving few centimeters above the acoustic panels. A brush is used to cover the rail cavity and minimize noise production. Some routing allows the cables to follow the acoustic array as it moves. The movement is ensured by an electric motor at a speed of few $\mathrm{cm} / \mathrm{s}$. The array is piloted from the wind tunnel control room either by sending commands to target a specific position or by ensuring a continuous movement until the end position. By recovering the electrical signal from the motor coding system we are able to record the actual position of the antenna in the test section via the acoustic data acquisition system. For this test we use an $85 G R A S$ Type $46 B D^{1 / 4}$ inch microphones acoustic antenna from previous studies ([2, 3, 14]). It consists in a 

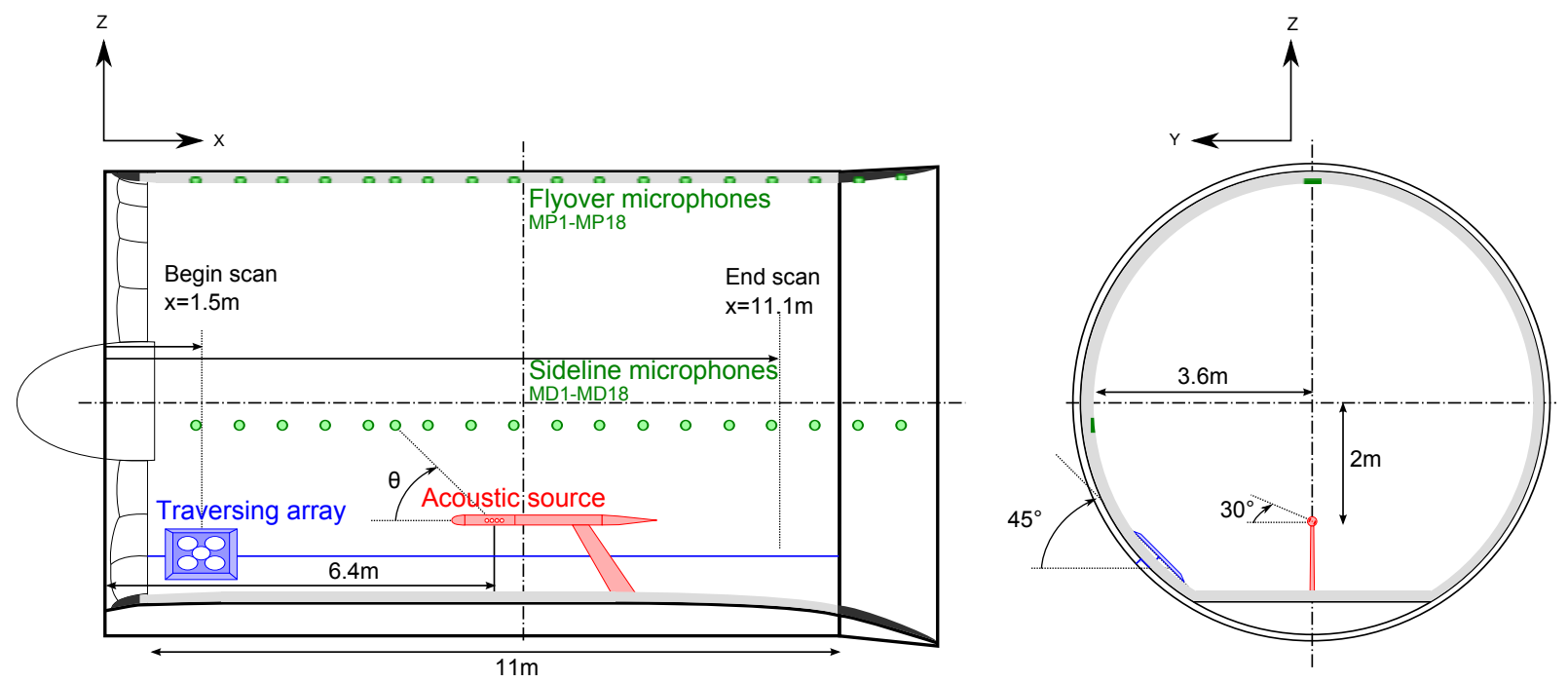

Fig. 2 Experimental setup.

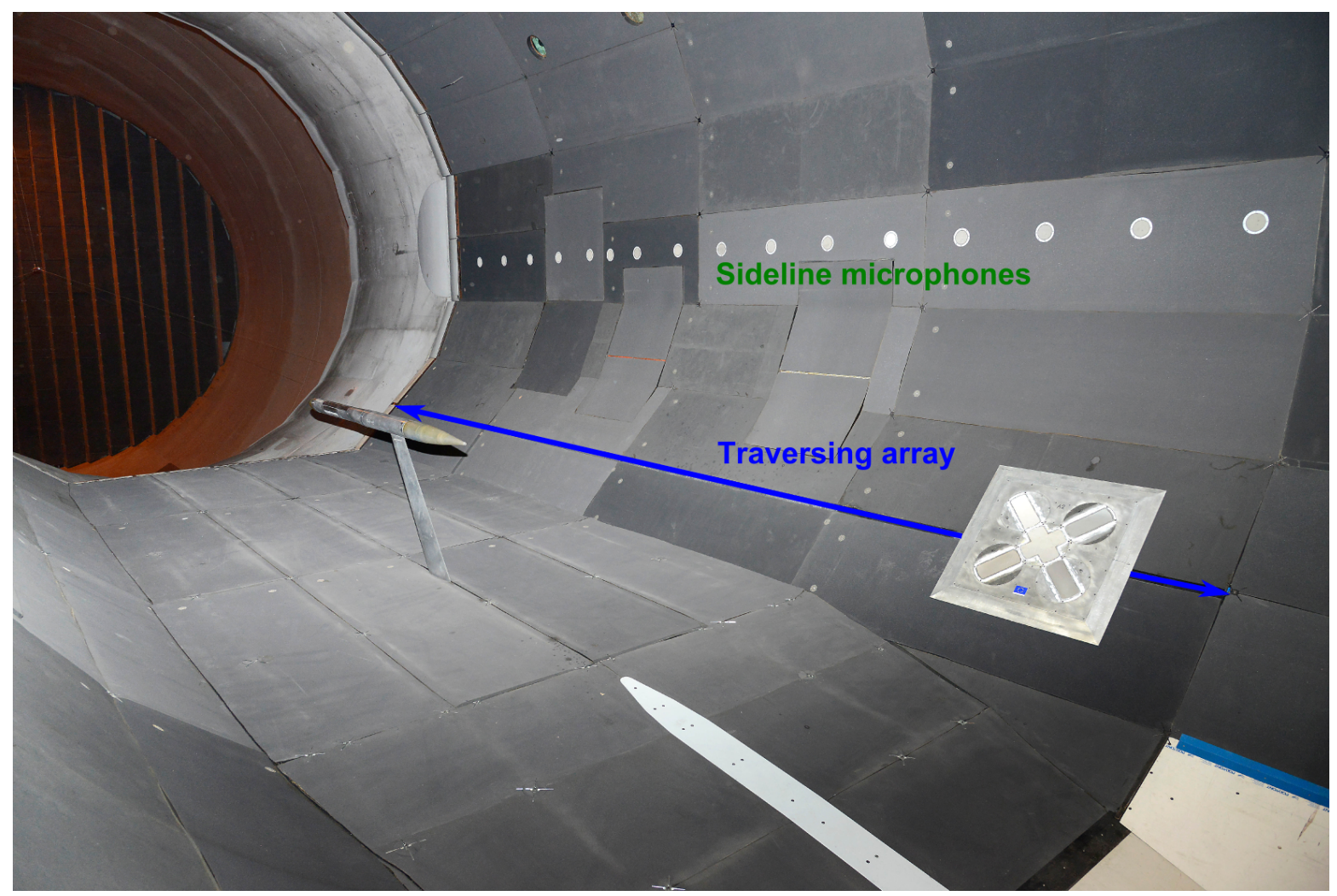

Fig. 3 Rear view of the test section showing the sideline microphones, the traversing array and the acoustic source.

cross-shaped microphone array with also wiremesh-covered recessed microphones. The position of the microphones are reminded in Fig. 5 . 


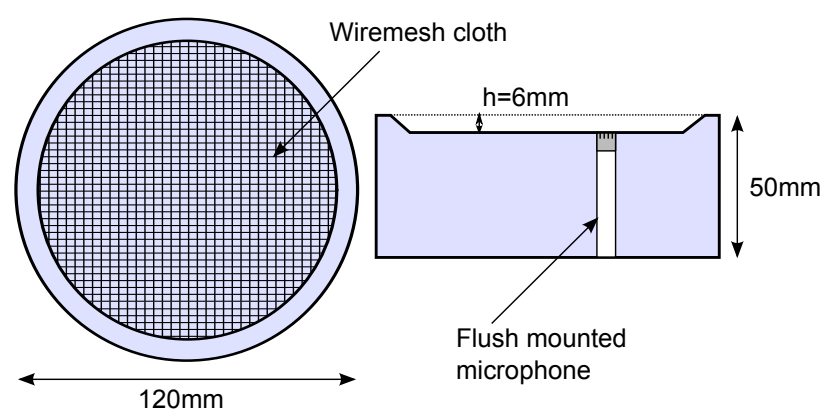

Fig. 4 Far-field microphones mount.
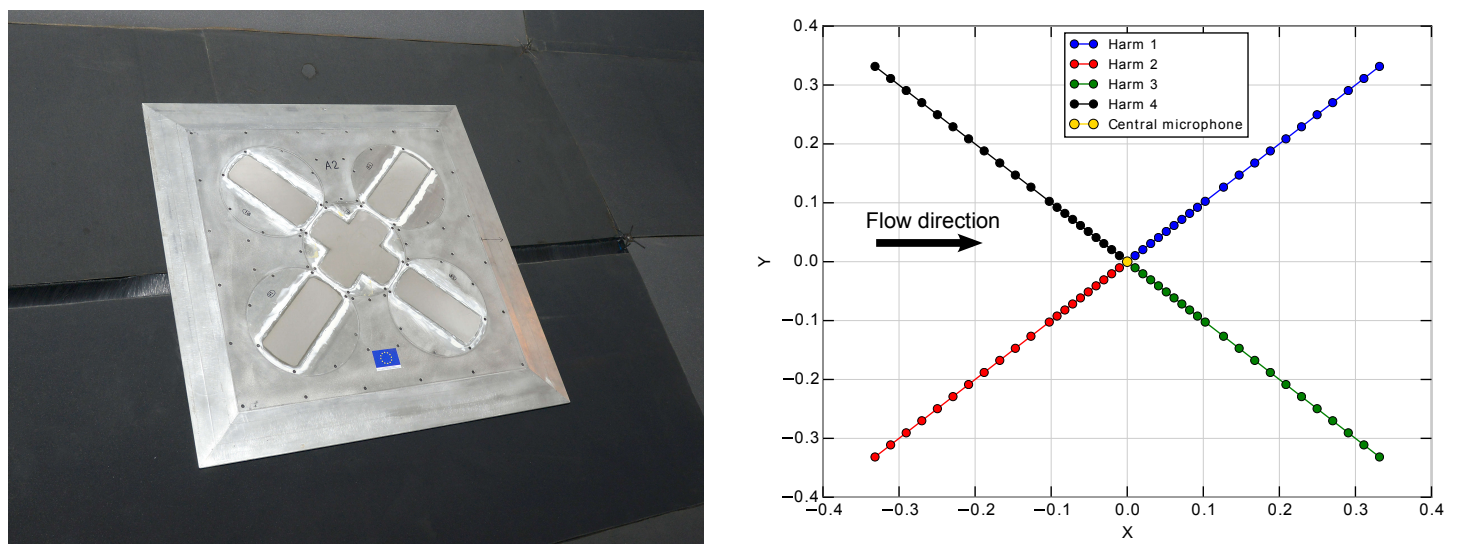

Fig. 5 Cross-shaped traversing array.

\section{Reference source}

In order to qualify the qualify the traversing array, we use the Witamotec source described in [2, 3, 14]. It consists of 4 BMS 4540 loudspeakers with a frequency range of [1.2 kHz; $30 \mathrm{kHz}$ ], embedded in an aerodynamic body (Fig. 6). The front of the source can be rotated, allowing to change the loudspeaker emission direction. For this test, the azimuthal angle $\phi_{0}$ is set to $30^{\circ}$ with respect to the horizontal direction, as specified in Fig 2, which is the direction of the sideline microphones. Control microphones allows us to monitor the noise emission of each loudspeaker individually. Here, only the loudspeaker \#1 and \#3 are used, either by generating a withe noise random signal or a so-called multi-sinus signal. The multi-sinus signal $s(t)$ mimics the acoustic response of an open-rotor or a fan engine. It is made of a superposition of sinus:

$$
s(t) \propto \sum_{p=p_{0}}^{p_{1}} \sin \left(2 \pi p \Delta_{f_{y}} t+\phi_{p}\right)
$$

where $p_{0}$ and $p_{1}$ are such that $p_{0} f_{y}=2 \mathrm{kHz}$ and $p_{1} f_{y}=20 \mathrm{kHz}$, with $\Delta f_{y}=256 \mathrm{~Hz}$.

Top view

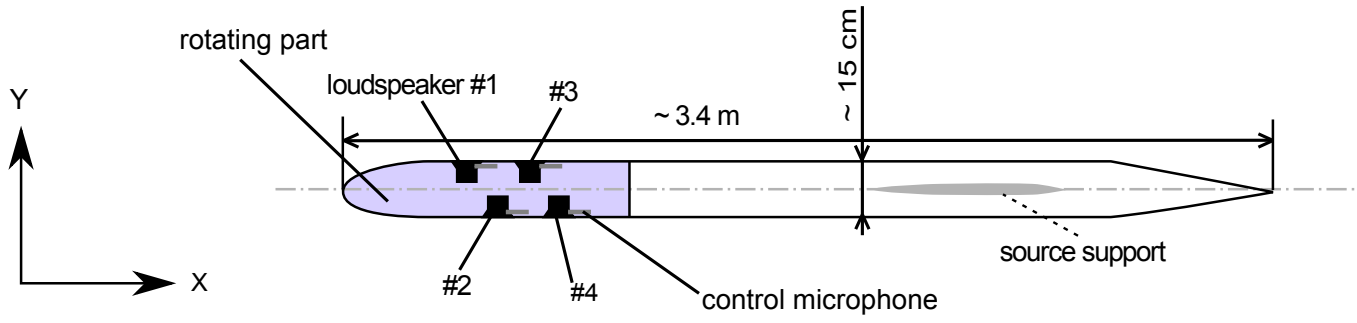

Fig. 6 Witamotec reference source equipped with four loudspeakers and theirs dedicated control microphones. 


\section{Data acquisition}

The different signals (far fields microphones, acoustic array, loudspeakers control microphones) are acquired at a sampling frequency $f_{s}=131072 \mathrm{~Hz}$ with our SYNAPS system. It consist of $L A N-X I B \& K$ modules linked to a switch and supervised by a master computer. The microphones channels are high-pass filtered at $22.4 \mathrm{~Hz}$. Three different kind of acquisitions are performed and detailed in Table 1 .

\begin{tabular}{c|c|c} 
Acquisition & Description & Time \\
\hline \hline $\begin{array}{c}\text { Fixed Position } \\
(\mathrm{FP})\end{array}$ & $\begin{array}{c}30 \mathrm{~s} \text { of acquisition at a given position/angle }\left(\Delta_{\theta}=1^{\circ}\right) \\
45 \mathrm{~min}\end{array}$ \\
\hline $\begin{array}{c}\text { Slow Continuous Scan } \\
\text { (Slow CS) }\end{array}$ & $\begin{array}{c}\text { Continuous acquisition along the rail length. } \\
\text { Array speed: } \sim 10 \mathrm{~cm} / \mathrm{s} .\end{array}$ & $4 \mathrm{~min} 50 \mathrm{~s}$ \\
\hline $\begin{array}{c}\text { Fast Continuous Scan } \\
\text { (Fast CS) }\end{array}$ & $\begin{array}{c}\text { Continuous acquisition along the rail length. } \\
\text { Array speed: } \sim 3.3 \mathrm{~cm} / \mathrm{s} .\end{array}$ & $1 \mathrm{~min} 35 \mathrm{~s}$ \\
\hline \hline
\end{tabular}

Table 1 Types of acquisitions.

\section{Fixed acquisitions}

In this section, we start by comparing Fixed Position (FP) measurements recorded by the acoustic array central microphone to the acoustic test section sideline microphones. This test, performed at no wind conditions (Mach=0.0), aims at verifying the good behavior of the traversing array system.

\section{A. Processing}

The following results and all FP acquisitions in this article are processed by a Fourier transform of 4096 length block size, providing a frequency resolution $\Delta f=32 \mathrm{~Hz}$. The sideline microphones are corrected from mounting effects based on calibration obtained in previous studies $([1,3])$. The same way, the acoustic antenna has been calibrated in anechoic chamber with an omnidirectional source ([3]). Thus, a correction based on the wiremesh attenuation, the piston mode in the gap between the microphones and the metallic cloth, and the $6 \mathrm{~dB}$ pressure doubling can be applied.

\section{B. High resolution directivity}

First and foremost, the homogeneity of the source in the azimuthal direction has been checked by rotating the source on its strut. In the range of angles $\phi_{0} \pm 35^{\circ}$ and below $12 \mathrm{kHz}$, the source directivity can be considered constant and allows us to compare both, the sideline microphone and the antenna central microphone FP measurements.

To investigate complex directivity radiation patterns we operates both loudspeaker \#1 and \#3 in phase, generating white noise.

For this comparison a fine discretization of $\Delta \theta=2^{\circ}$ has been achieved for the acoustic array acquisition as a reference. Figure 7 shows third-octave band directivity normalized at a source distance of $1 \mathrm{~m}$ for band 32, 35, 38 and 39 . To check the stationarity of the acoustic source during the 45 min acquisition of the array FP, sideline microphones directivity at the beginning and the end of the test are plotted.

From the four directivity plots of Figure 7 we can see a fairly good agreement between the the two kind of instrumentation. Some discrepancies are present, in particular at high directivity angle and low frequency where the mounting correction is delicate to tackle. Finally, it is clear from the $8 \mathrm{kHz}$ third octave band spectrum that the sideline microphones under-samples the complex directivity pattern whereas the traversing array is able to recover the multiple lobs. In previous acoustic tests, the source directivity was sometimes difficult to analyze only from sidelines microphone sampling. The new traversing array can overcome this problem and offers substantial physical analysis.

Although the traversing array is capable of analyzing complex acoustic sources, it requires a large amount of time. Indeed, the results from Fig. 7 has involved the acquisition from 60 individual positions, representing an important effort. In order to improve the wind tunnel productivity continuous scans are investigated in the following Section. 

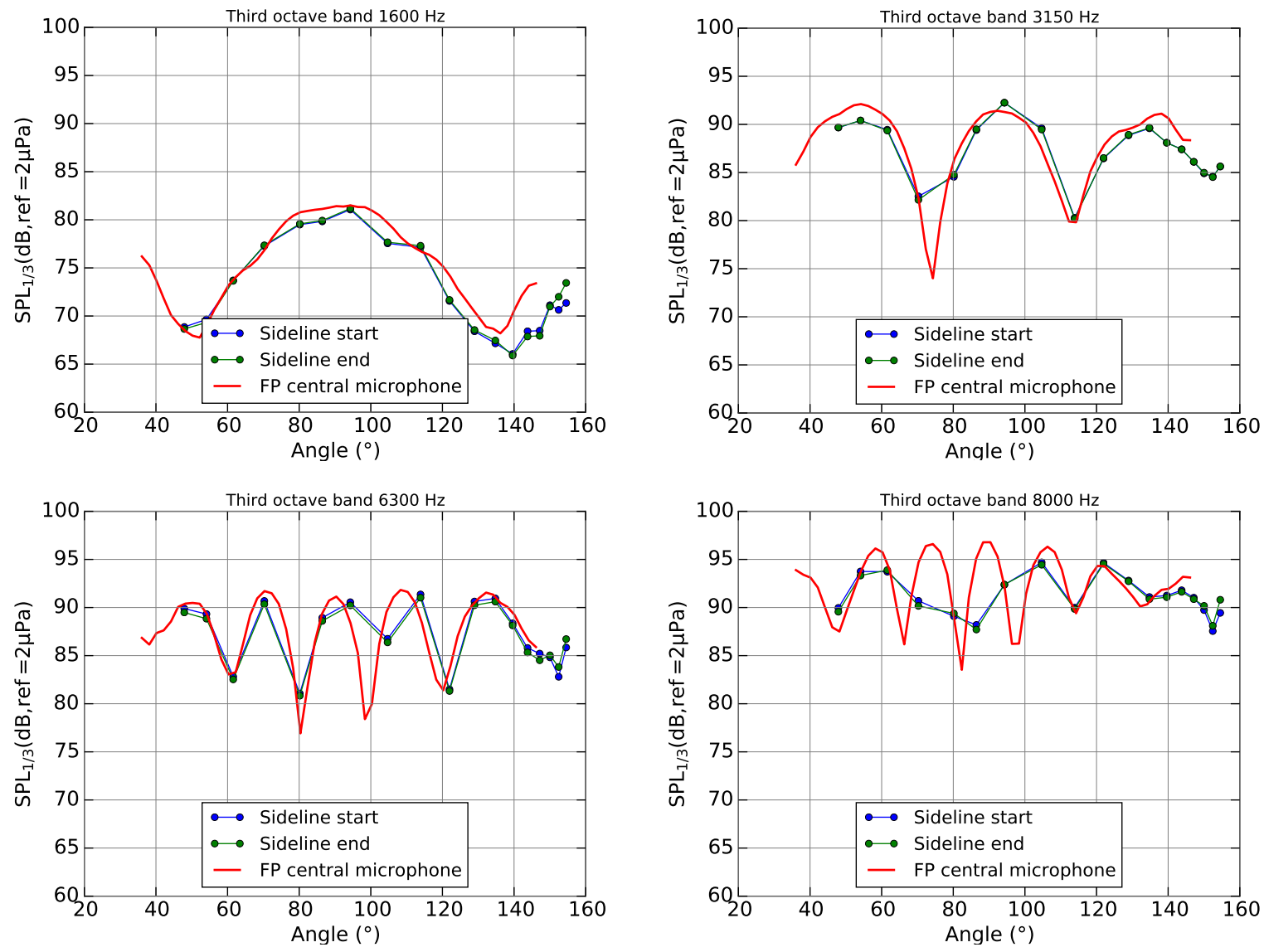

Fig. 7 Third-octave band directivity for the sideline microphones and the traversing array central microphone.

\section{Continuous scans}

\section{A. Continuous scan processing}

To process the continuous scans we proceed as follow. First, we define the angular positions $\theta_{i}$ where measurements are desired. Then, for each position, we compute a fast Fourier transform on constant time interval centered on the angular position. Classically, the time interval is divided into blocs in order to improve the spectrum estimation. By doing so, we ensure that each point is computed with the same FFT parameters. In the latter results, we used 4096 points blocs as FP measurements and time interval of $1.25 \mathrm{~s}$. Those choices allow us to have the same frequency resolution as FP data and they have been found as a good compromise between bias and variance for spectrum computation. While following CS results are extracted with a spacing $\Delta_{\theta}=2^{\circ}$ there is no practical limit for better resolution. This choice was found to be sufficient for capturing our source directivity pattern. Note that no Doppler correction has been implemented considered the acoustic array low velocity. The validity of this choice is further analyzed in the following.

\section{B. Traversing array characterization}

Before using the traversing array in operating conditions, we have performed several tests to assess the impact of such device in the test section.

Firstly, we have measured the additional noise due the the traversing array motor. On Fig. 8, we compare the power spectrum density (PSD) obtained at $\theta=50^{\circ}$ for the fixed position (FP) acquisition to the two continuous scans (CS).

As it can be see, few tones are present at low frequency due to the motor. At higher speed, a broadband contribution is added. Nevertheless, the motor noise contribution is very low and underneath the wind tunnel self noise (Fig. 9) when operating. One would also noticed the peak around $1040 \mathrm{~Hz}$ for FP measurements which is probably due to environmental noise around the wind tunnel or residual noise from the source. 


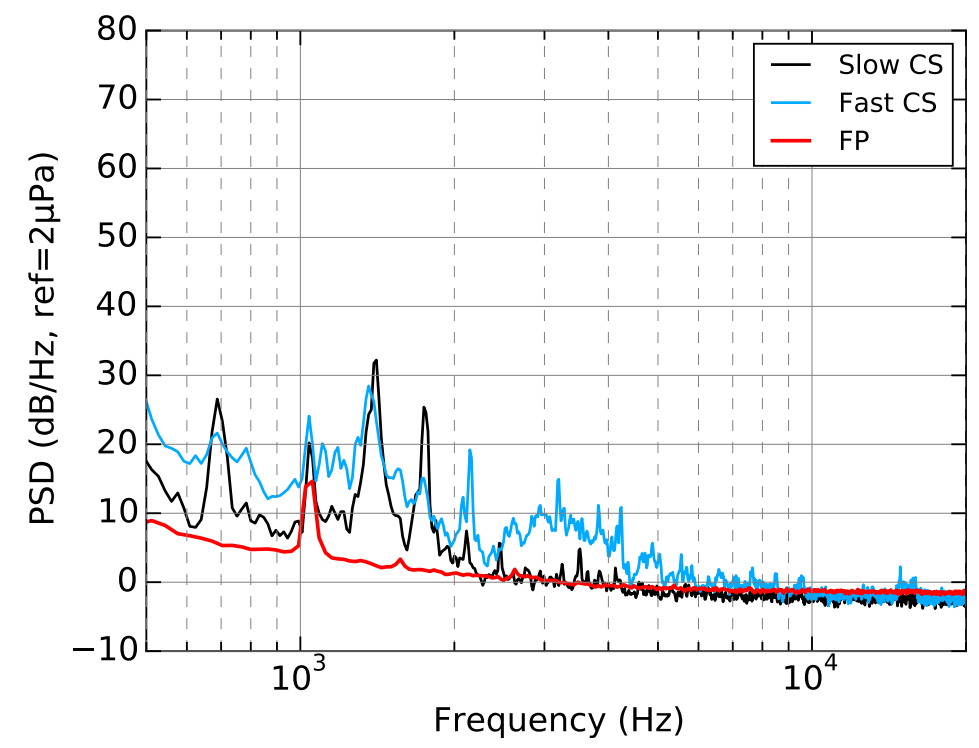

Fig. 8 Impact of the traversing array motor noise $\left(\theta=50^{\circ}, M=0.0\right)$.

On Fig. 9 the wind tunnel background noise is also compare to a previous test campaign from 2016, before the installation of the traversing array. Thanks to the particular attention paid to the system mount, no additional noise is produce by the antenna. One can also note the very good reproductivity between the two test campaigns.

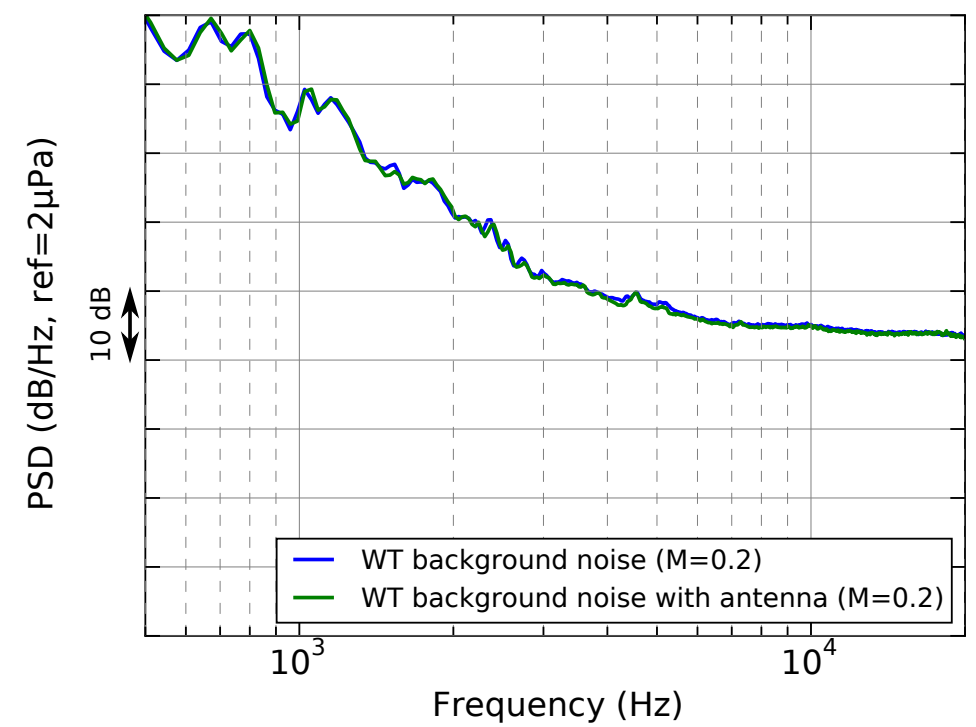

Fig. 9 Impact of the traversing array on the Wind Tunnel background noise. PSD from sideline microphone $M D 7$ at $M=0.2$.

\section{Continuous scans measurements in flow conditions}

In the following, we investigate the performance of continuous scans (CS) at Mach 0.2 for three different noise emission. On each case, we compare power spectrum density at $70^{\circ}$ polar angle and third octave band spectra. Please note that, due to variations in the source emission, some figures show only one CS. 
First, multi-sinus source emission on loudspeaker \#3 at Mach 0.2 is investigated. Figure 10 shows the PSD at $70{ }^{\circ}$ polar angle. All three acquisitions agree well. In Fig. 11, a zoom in linear scale is provided for $\theta=150^{\circ}$. It confirms that no Doppler effect impacts the quality of the data.

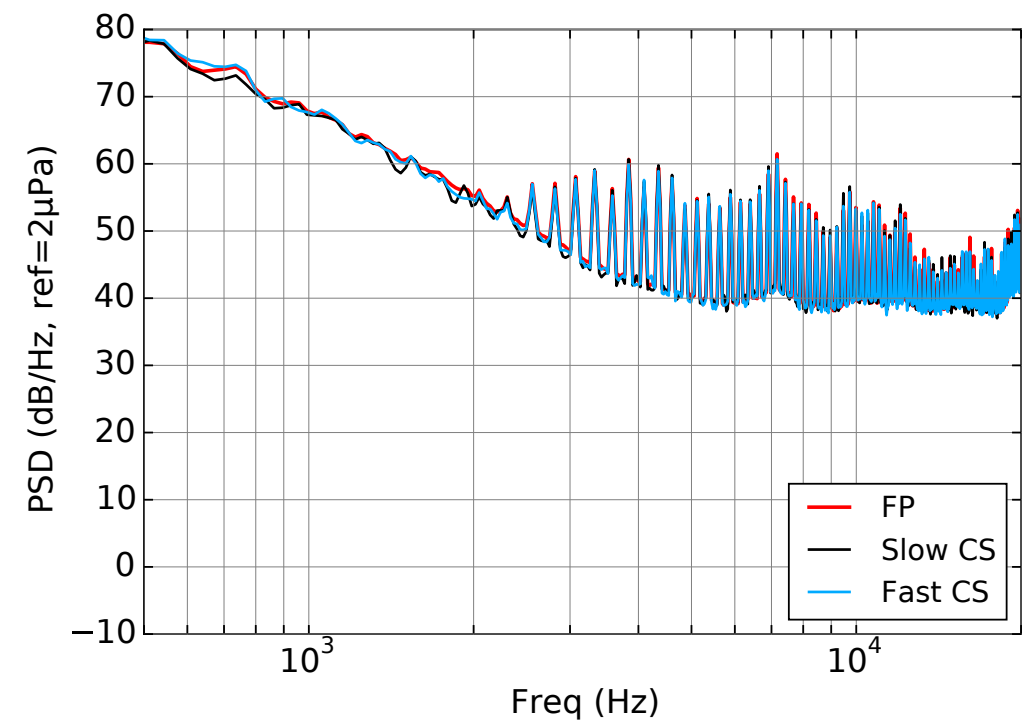

Fig. 10 Comparison of traversing array central microphone Fixed Position (FP) measurement and Continuous Scans (CS) acquisitions at $\theta=70^{\circ}$. Loudspeaker \#3 multi-sinus source emission at Mach 0.2.

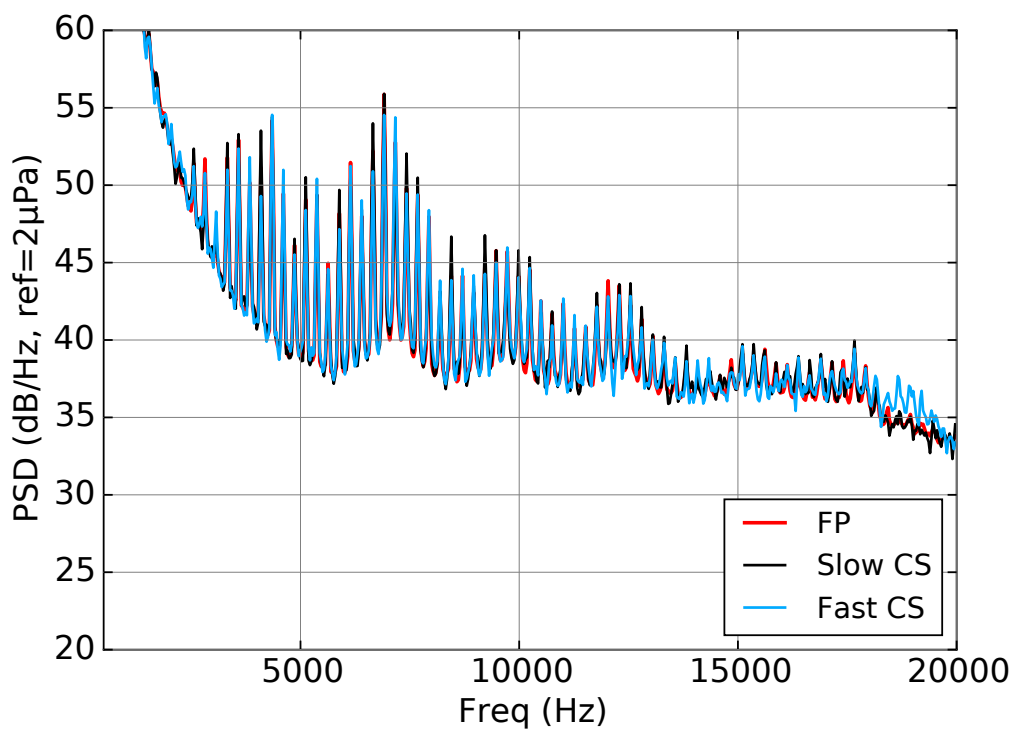

Fig. 11 Comparison of traversing array central microphone Fixed Position (FP) measurement and Continuous Scans (CS) acquisitions at $\theta=150^{\circ}$. Loudspeaker \#3 multi-sinus source emission at Mach 0.2.

The multi-sinus third octave band directivity presented in Fig. 12 confirmed the very good agreement between FP and CS acquisitions.

Similar results are given in Fig 13 and Fig 14 for white noise emission on loudspeaker \#3, and in Fig 15 and Fig 16 when operating loudspeakers \#1 and \#3 in opposite phase with correlated white noise. In all situations continuous scans 

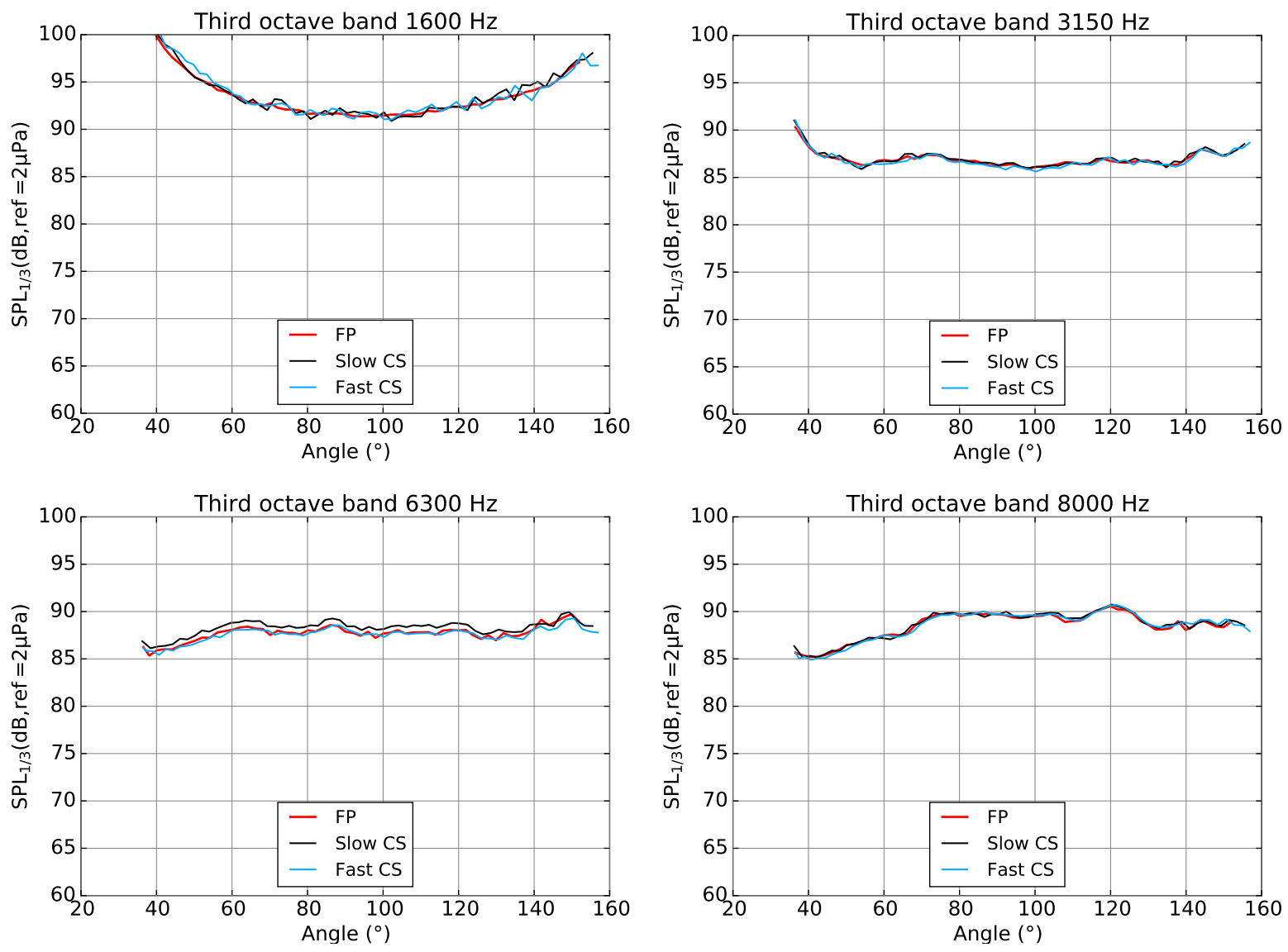

Fig. 12 Third-octave band directivity for traversing array central microphone Fixed Position (FP) measurement and Continuous Scans (CS) acquisitions. Loudspeaker \#3 multi-sinus source emission at Mach 0.2.

performed very well compared to fixed positions measurements. The traversing array combined with CS scans offers both the ability of fine noise diagnostics while maintaining the impact on wind tunnel tests very low. 


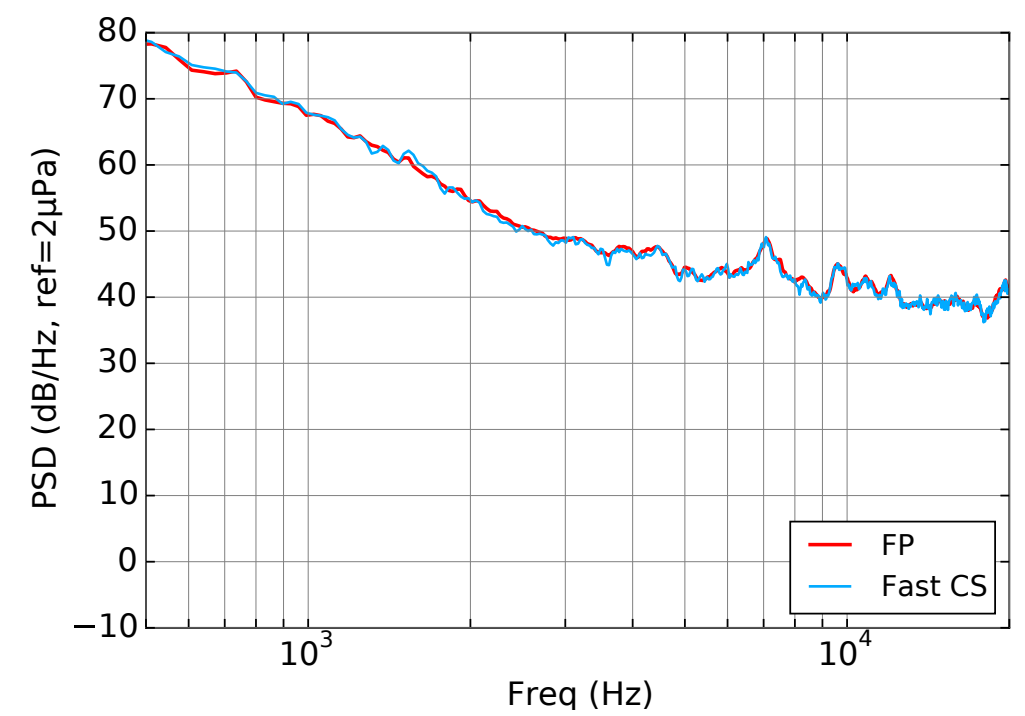

Fig. 13 Comparison of traversing array central microphone Fixed Position (FP) measurement and Continuous Scans (CS) acquisitions at $\theta=70^{\circ}$. Loudspeaker \#3 white noise source emission at Mach 0.2 .
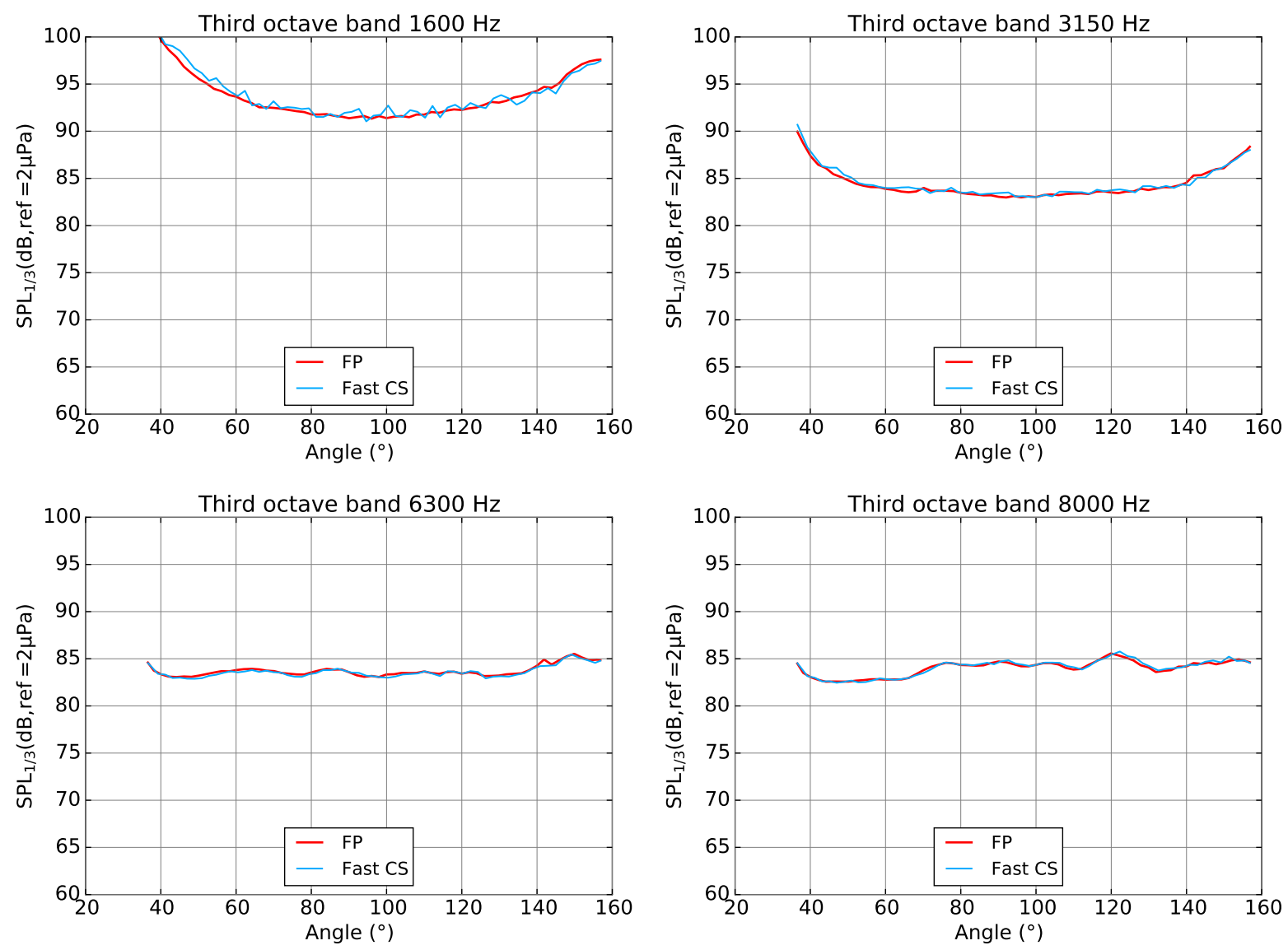

Fig. 14 Third-octave band directivity for traversing array central microphone Fixed Position (FP) measurement and Continuous Scans (CS) acquisitions. Loudspeaker \#3 white noise source emission at Mach 0.2. 


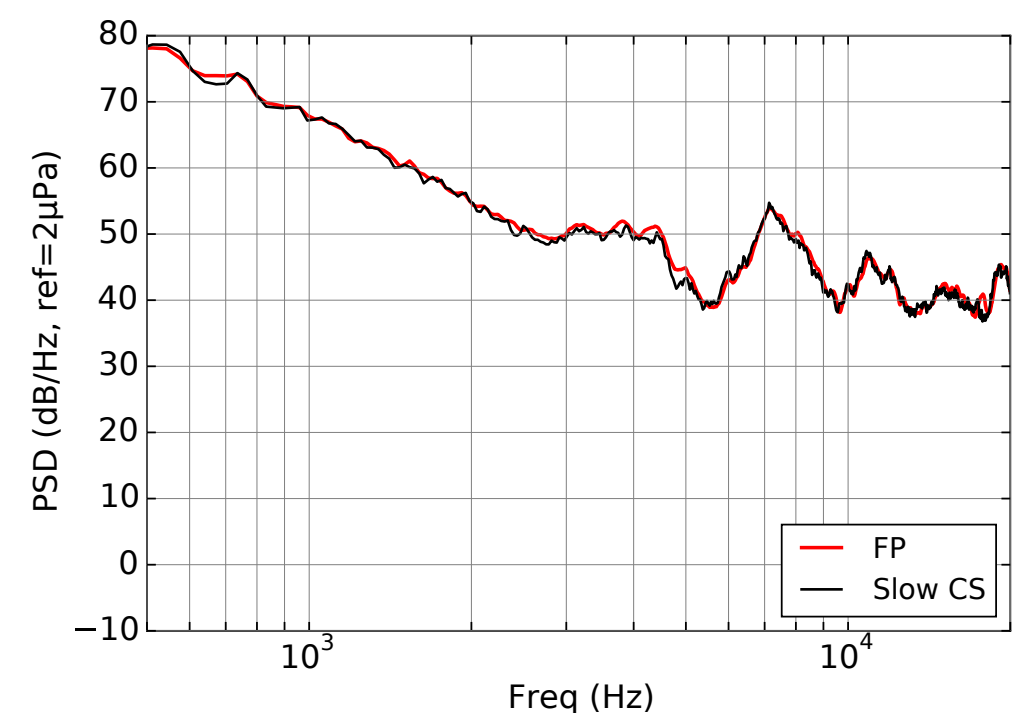

Fig. 15 Comparison of traversing array central microphone Fixed Position (FP) measurement and Continuous Scans (CS) acquisitions at $\theta=70^{\circ}$. Loudspeakers \#1 and \#3 white noise source emission at Mach 0.2 .
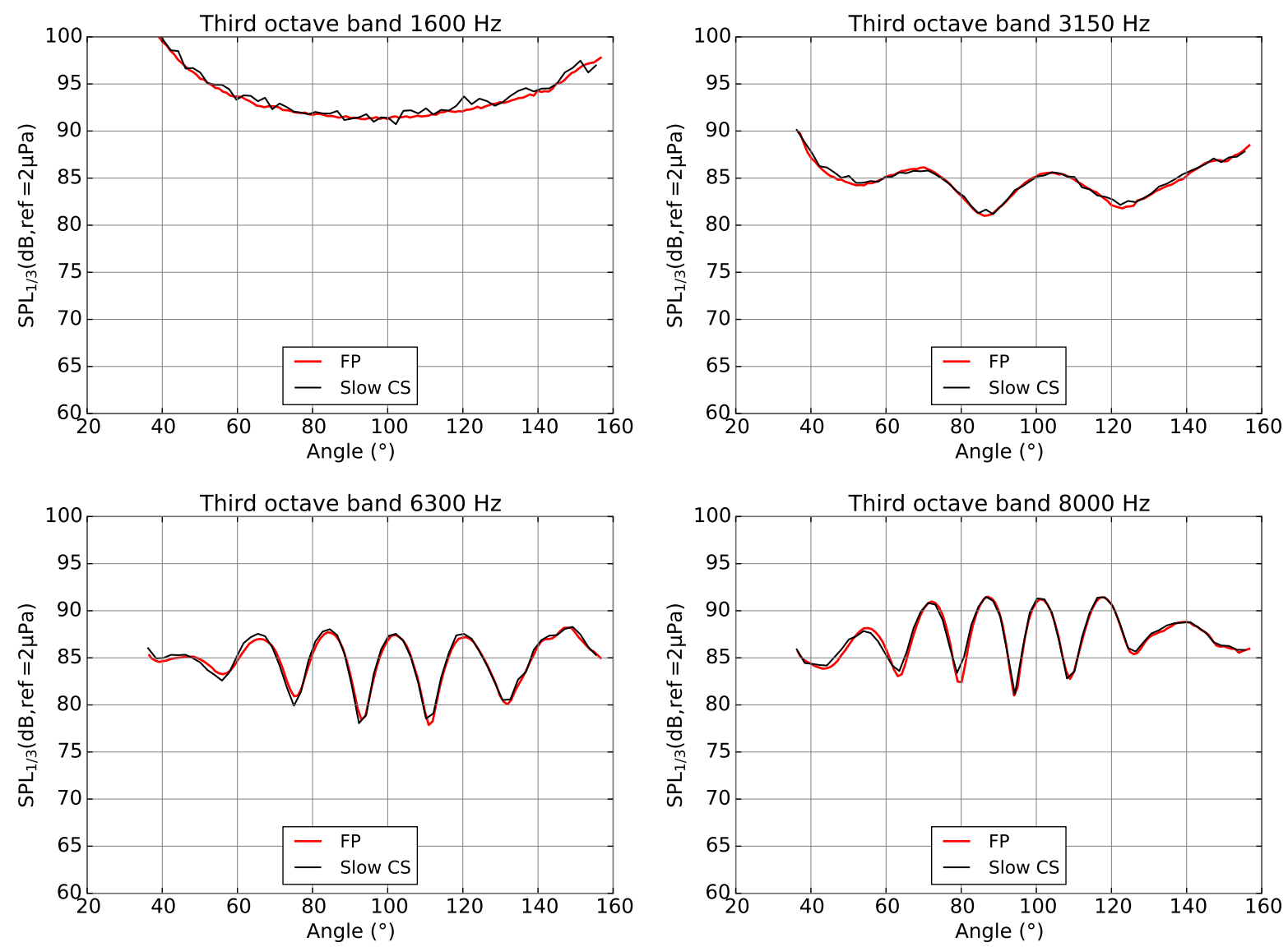

Fig. 16 Third-octave band directivity for traversing array central microphone Fixed Position (FP) measurement and Continuous Scans (CS) acquisitions. Loudspeakers \#1 and \#3 opposite phase white noise source emission at Mach 0.2. 


\section{Beamforming dereverberation}

\section{A. Context}

Although the test section is equipped with acoustic liner and the reverberation is minimized, we take advantage of the acoustic array to apply standard beamforming on the data. This preliminary work can serve as a reference for future tests without the acoustic liner, in particular for high speed measurement. Moreover, the signal-to-noise ratio can also benefits from the use of beamforming technique.

The use of acoustic antenna in hard-wall closed-section wind tunnel can be a difficult problem due to strong reverberation. To overcome this difficulty, different approaches have been studied. On one side, numerical techniques aims at modifying the free field Green function in order to take into account the influence of reflections. Indeed, for rectangular test sections, mirror sources can be easily estimated and incorporated in the beamforming process. Using its Image Source Model (ISM) approach Fenech [15] shown that the first order reflections have the strongest impact on the beamforming process. Another approach developed by Sijtsma [16] consist in reducing the influence of virtual sources based on their coherence with real one. On a another side, Fisher [17] experimentally characterized his test section impulse response and used it in the beamforming process rather than the free-field Green function. Under the constrain of using a very fine mesh, Fisher shows the relevance of the method which overcome IMS in his case.

In our case both previous approaches seem quite difficult to use. Indeed, the complex geometry of the test section makes the use of IMS complex to tackle. Moreover, depending on the nature and localization of the source in the test section, this option does not seem suitable for industrial wind tunnel test. On the other hand, the experimental characterization of the impulse response is not viable neither considering the mesh finesse required and the test section size. The test section size is however valuable to ease the separation of real sources from virtual ones. For those reasons, we apply conventional beamforming based on a specific processing for cross shaped antennas developed by Elias [18].

\section{B. Dereverberation}

As explained before, we use beamforming technique to localize the real source on a mesh of $50 \times 50$ points with a spacing $\Delta X=\Delta Z=10 \mathrm{~cm}$. The corresponding coherence map for a frequency of $5 \mathrm{kHz}$ is shown on Fig. 17. As indicated, for high frequency the source maximum correctly located. Then, by extracting the maximum of coherence for each frequency we can reconstruct the antenna central microphone dereverberated spectrum.

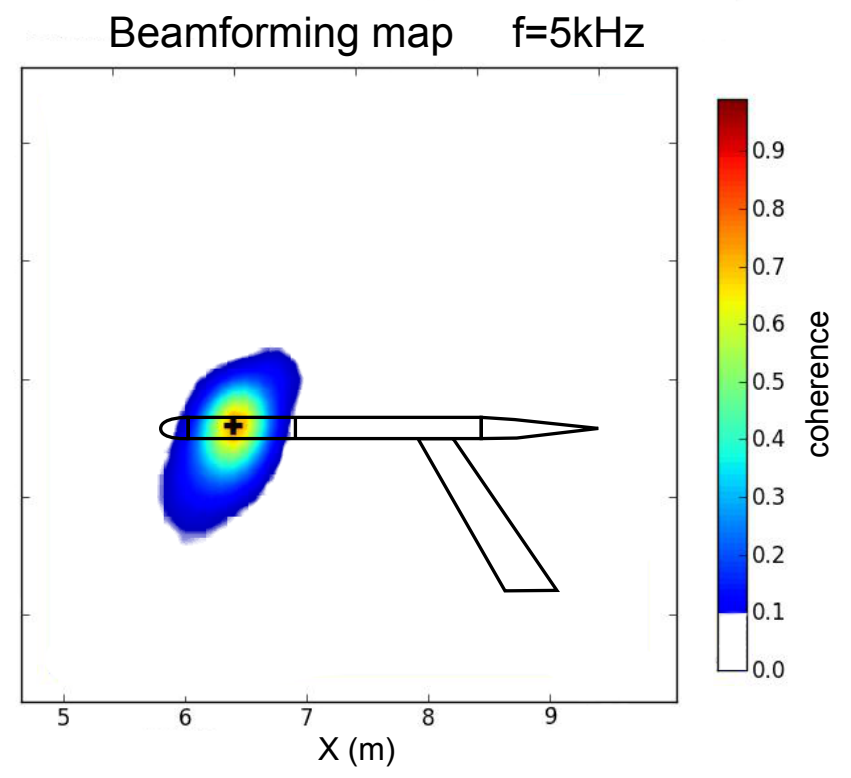

Fig. 17 Beamforming map at a frequency of $5 \mathrm{kHz}$.

Figure 18 shows the spectrum at $\theta=90^{\circ}$ angle normalized at a distance of $1 \mathrm{~m}$ for a white noise emission on loudspeaker \#3. For indication, the control microphone of loudspeaker \#3 is also plotted in Fig. 18 in green color. The 
beamforming process clearly enhanced the source measurement by increasing the signal to noise ratio by almost $15 \mathrm{~dB}$. It also helps to better recover the source signal.

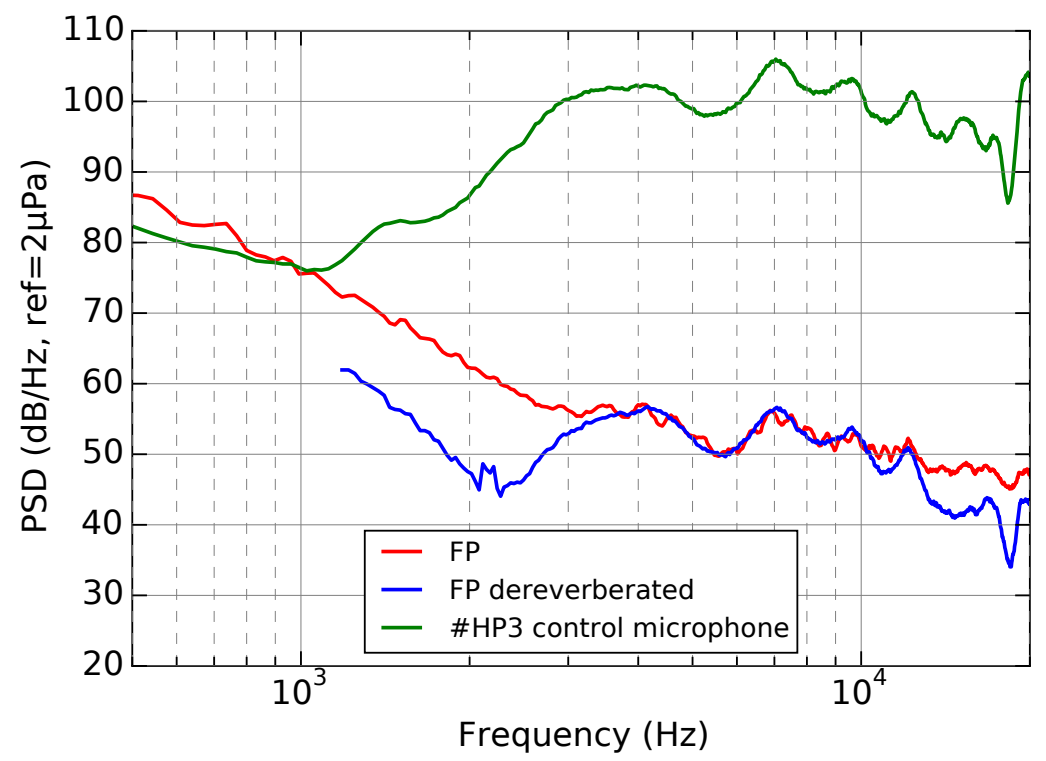

Fig. 18 Comparison of traversing array central microphone raw spectrum and dereverberated one at $\theta=90^{\circ}$. Loudspeaker \#3 white noise source emission at Mach 0.2.

This first application of beamforming on the traversing array still need to be further investigated. However, it shows very promising results in particular in reducing the non-coherent aerodynamic noise.

\section{Conclusion}

In this paper we have described the use of a traversing array in the acoustic closed test section of S1MA wind tunnel. Preliminary results show the great interest of such a device in capturing complex source directivity. Taking advantage of the continuous scans acquisitions fine source characterization has been made while minimizing the impact on wind tunnel productivity: same measurement quality is achieved through $1 \mathrm{~min} 35$ s Continuous Scans (CS) rather than $45 \mathrm{~min}$ acquisitions at Fixed Position (FP). Finally, the use of an acoustic array also allows us to perform dereverberation using conventional beamforming processing showing promising results on denoising. This ability would be of great benefit for future tests without the acoustic liner, allowing acoustic measurements higher than Mach 0.3.

\section{References}

[1] Méry, F., Rey, M., Davy, R., and Fernando, R., "Far field wall-mounted microphone device for the S1MA anechoic closed-section wind tunnel applied to Open Rotor," 18th AIAA/CEAS Aeroacoustics Conference (33rd AIAA Aeroacoustics Conference), 2012, p. 2228.

[2] Méry, F., "S1MA High Speed Acoustic Measurement Devices for Open Rotor Mock Up," 19th AIAA/CEAS Aeroacoustics Conference, 2013, p. 2253.

[3] Méry, F., Davy, R., Fleury, V., Bulté, J., and Rey, M., "Beamforming-based noise level dereverberation solution for S1MA sonic wind-tunnel: metrology, methodology and validation," 21st AIAA/CEAS Aeroacoustics Conference, 2015, p. 3274.

[4] Sinnige, T., Ragni, D., Eitelberg, G., and Veldhuis, L. L., "Pusher-Propeller Installation Effects in Angular Inflow," 22nd AIAA/CEAS Aeroacoustics Conference, 2016, p. 2875.

[5] Grumman, N., "Hybrid wing body aircraft acoustic test preparations and facility upgrades," 2013. 
[6] Spalt, T. B., Brooks, T. F., Bahr, C. J., Plassman, G. E., Becker, L. E., and Stead, D. J., "Calibrations of the NASA Langley 14-by 22-Foot Subsonic Tunnel in Acoustic Configuration," AIAA Paper accepted for presentation at the 20th Aeroacoustics Conference in Atlanta, GA (June 2014), 2014.

[7] Humphreys Jr, W. M., Brooks, T. F., Bahr, C. J., Spalt, T. B., Bartram, S. M., Culliton, W. G., and Becker, L. E., "Development of a Microphone Phased Array Capability for the Langley 14-by 22-foot Subsonic Tunnel," AIAA 2014, Vol. $2343,2014$.

[8] Doty, M. J., Brooks, T. F., Burley, C. L., Bahr, C. J., and Pope, D. S., "Jet noise shielding provided by a hybrid wing body aircraft," AIAA paper, Vol. 2625, 2014.

[9] Hutcheson, F. V., Brooks, T. F., Burley, C. L., Bahr, C. J., Stead, D. J., and Pope, D. S., "Shielding of Turbomachinery Broadband Noise by a Hybrid Wing Body Aircraft Configuration," AIAA paper, Vol. 2624, 2014.

[10] Horne, W. C., Burnside, N. J., Soderman, P. T., Jaeger, S. M., Reinero, B. R., James, K. D., and Arledge, T. K., "Aeroacoustic Study of a 26\%-Scale Semispan Model of a Boeing 777 Wing in the NASA Ames 40-by 80-Foot Wind Tunnel," 2004.

[11] Burnside, N. J., Horne, W. C., Elmer, K. R., Cheng, R., and Brusniak, L., "Phased Acoustic Array Measurements of a 5.75 Percent Hybrid Wing Body Aircraft," 2016.

[12] Shah, P. N., Vold, H., Hensley, D., Envia, E., and Stephens, D., "A High-Resolution Continuous-Scan Acoustic Measurement Method for Turbofan Engine Applications," Journal of Turbomachinery, Vol. 137, No. 12, 2015, p. 121002.

[13] Fleury, V., Coste, L., Davy, R., Mignosi, A., Cariou, C., and Prosper, J.-M., "Optimization of microphone array wall mountings in closed-section wind tunnels," AIAA journal, Vol. 50, No. 11, 2012, pp. 2325-2335.

[14] Fleury, V., and Davy, R., "Beamforming-based noise level measurements in hard-wall closed-section wind tunnels," Proceedings of the 18th AIAA/CEAS Aeroacoustics Conference, 2012, pp. 1-22.

[15] Fenech, B., and Takeda, K., "Towards more accurate beamforming levels in closed-section wind tunnels via de-reverberation," 13th AIAA/CEAS Aeroacoustics Conference (28th AIAA Aeroacoustics Conference), 2007, p. 3431.

[16] Sijtsma, P., and Holthusen, H., "Corrections for mirror sources in phased array processing techniques," 9th AIAA/CEAS Aeroacoustics Conference and Exhibit, 2003, p. 3196.

[17] Fischer, J., and Doolan, C., "Beamforming in a reverberant environment using numerical and experimental steering vector formulations," Mechanical Systems and Signal Processing, Vol. 91, 2017, pp. 10-22.

[18] Elias, G., "Source localization with a two-dimensional focused array- Optimal signal processing for a cross-shaped array," INTER-NOISE 95, 1995, pp. 1175-1178. 